\title{
Studies of Factors V and VIII:C in an Animal Model of Disseminated Intravascular Coagulation
}

\author{
Alan R. Giles, Michael E. Nesheim, and Kenneth G. Mann \\ Departments of Pathology and Medicine, Queen's University and \\ Kingston General Hospital, Kingston, Ontario, Canada; \\ Section of Hematology Research, Mayo Clinic, \\ Rochester, Minnesota 55905
}

bstract. An experimental animal model of disseminated intravascular coagulation (DIC) induced by the co-infusion of coagulant-active phospholipid and activated Factor $\mathrm{X}$ (Factor $\mathrm{Xa}$ ) is described. The infusion of Factor $\mathrm{Xa}$ at a dose of $6.6 \times 10^{-12} \mathrm{~mol} / \mathrm{kg}$ with phosphatidylcholine/phosphatidylserine (PCPS) lipid vesicles at a dose of $4.0 \times 10^{-8} \mathrm{~mol} / \mathrm{kg}$ was associated with significant falls in the levels of fibrinogen and Factors V and VIII, and a bleeding diathesis developed. Assays of Factors V and VIII were performed by a onestage prothrombin time and activated partial thrombin time system, respectively. In additional experiments, the effect of the same dose combination of Factor $\mathrm{Xa} / \mathrm{PCPS}$ on Factor $\mathrm{V}$ kinetics was studied by preinfusing ${ }^{125}$ I-labeled Factor V. After Factor Xa/PCPS infusion, Factors VIII and V were reduced at 2 min by 90 and $50 \%$ of the preinfusion levels, respectively, and at $1 \mathrm{~h}$ by 80 and $75 \%$, respectively. During the same period, there was litle change in the total circulating radioactivity. Autoradiography indicated small but detectable levels of circulating proteolytic products of Factor $\mathrm{V}$ that comigrated with peptides obtained by the incubation of Factor $\mathrm{V}$ with Factor $\mathrm{Xa}$ and activated protein $\mathrm{C}$. The majority of radioactivity remained associated with the intact single-chain precursor Factor V. These observations suggested maintenance of the precursor pool after the onset of DIC. This was confirmed by performing two-stage assays of Factors V and VIII, whereby each was completely converted to the active cofactor, i.e., Va

This work was presented in part at the IXth International Meeting of the International Society of Thrombosis and Hemostasis, Stockholm, Sweden, July, 1983.

Received for publication 2 November 1983 and in revised form 31 July 1984.

J. Clin. Invest.

(c) The American Society for Clinical Investigation, Inc.

0021-9738/84/12/2219/07 \$1.00

Volume 74, December 1984, 2219-2225 and VIII:Ca, by preincubation of the test sample with thrombin before assaying in a one-stage system as before. The Factor $\mathrm{V}$ levels assayed by the two-stage procedure did not change appreciably over $1 \mathrm{~h}$. The Factor VIII levels fell but corrected within $1 \mathrm{~h}$ at a time when the level measured by a one-stage assay remained depressed. These results indicate that in the dog, infusion of Factor $\mathrm{Xa} / \mathrm{PCPS}$ induces changes characteristic of DIC, and this is associated with the appearance of Factor $\mathrm{V}$ peptides characteristic of the expression of Factor $\mathrm{Xa}$ and activated protein $\mathrm{C}$-like activities. The differences noted between the one-stage and two-stage assays suggest that the one-stage assay is measuring the activated fraction of each cofactor and not the total level of the available precursor for each activated species. The results suggest a close correlation between the activated fraction of both cofactors and the hemostatic abnormality that occurs in DIC.

\section{Introduction}

The etiological factors involved in the development of disseminated intravascular coagulation (DIC) ${ }^{1}$ are multiple. Experimental and clinical data are consistent with the concept of its initiation after increased intravascular procoagulant activity. This is subsequently modified more or less by the functional status of the individual's inhibitory or protective mechanisms (1). DIC is a known complication of therapy with prothrombin complex concentrates (PCC) (2). This is seen more frequently in either patients with liver disease or neonates $(3,4)$. As all PCC are known to be contaminated with activated products of the component clotting factors, i.e., Factors II, VII, IX, and $\mathrm{X}$, it has generally been assumed that a principal etiological factor in this association is the infusion of procoagulant material into patients whose reticuloendothelial cell function

1. Abbreviations used in this paper: APC, activated protein C; APTT, activated partial thromboplastin time; CBT, cuticle bleeding time; DIC, disseminated intravascular coagulation; PCC, prothrombin complex concentrates; PCPS, phosphatidyl-choline/phosphatidylserine. 
(clearance) is compromised (5). Studies from our laboratories have demonstrated that coagulant-active phospholipid acts synergistically with activated Factor X (Factor Xa) and potently amplifies its thrombogenic potential in vivo (6). Moreover, in normal animals it is the content of this component in any one PCC preparation that most closely correlates with thrombogenicity measured in vivo (6). Using purified components, i.e., Factor Xa and phosphatidylcholine/phosphatidylserine (PCPS) lipid vesicles as a source of coagulant-active phospholipid, we have been able to mimic the effects found with coagulantactive phospholipid-rich PCC preparations (6). In this report, we present data from experiments performed in dogs in which the infusion of precise formulations of PCPS lipid vesicles and Factor $\mathrm{Xa}$ in combination resulted in clinical and laboratory evidence of DIC with notable similarities to the human clinical condition.

\section{Methods}

Coagulation assays. Blood was collected by venipuncture using a 21-gauge butterfly needle (Abbott-Ireland, Sligo, Ireland) and a twosyringe technique. The anticoagulant used was sodium citrate $(3.8 \%$ $\mathrm{wt} / \mathrm{vol}$ ); 9 vol of blood to 1 vol anticoagulant in plastic tubes. Plateletpoor plasma was separated by centrifugation at $2,500 \mathrm{~g}$ for $15 \mathrm{~min}$ at $4^{\circ} \mathrm{C}$. In most cases, the plasma was snap-frozen and stored at $-70^{\circ} \mathrm{C}$ until processed as described below.

Factors V and VIII:C were assayed by one- and two-stage assays. In the one-stage assays, Factors $\mathrm{V}$ and VIII:C were measured by a prothrombin time and an activated partial thromboplastin system, respectively, as previously described (7). In each case, a normal pool obtained from 20 normal dogs was used as a reference standard. In the two-stage assays of Factor V, the plasma sample to be assayed was diluted 1:50 and then thrombin-activated $(1 \mathrm{U} / \mathrm{ml}$, final concentration) for $1 \mathrm{~min}$ at $37^{\circ} \mathrm{C}$ before being assayed as described for the one-stage assay. We have previously reported that, under these conditions, complete conversion of Factor $\mathrm{V}$ to thrombin-activated purified Factor $\mathrm{V}$ (Factor Va) occurs (8). In the two-stage assay of Factor VIII, the Factor VIII-deficient substrate plasma was incubated with the activated partial thromboplastin time (APTT) reagent for $4.75 \mathrm{~min}$, at which point the test plasma, previously thrombin activated for $1 \mathrm{~min}$ as described for the Factor $\mathrm{V}$ assay, was added. $15 \mathrm{~s}$ later, $25 \mathrm{mM}$ calcium chloride was added and the clotting time recorded. Plasma samples assayed in this way were processed immediately after the separation of platelet-poor plasma from freshly collected blood.

Fibrinogen was measured as the thrombin-clottable protein by the method of Clauss (9) using a fibrometer (BBL Microbiology Systems, Div. Becton Dickinson Co., Cockeysville, MD) and purified bovine thrombin. Platelet counts were measured in EDTA anticoagulated whole blood using a Super-S particle counter (Coulter Electronics Inc., Hialeah, FL). Heparin assays were performed by chromogenic assay of Factor Xa inhibition as described by Teien et al. (10).

Plasminogen activator activity was measured using lysine-agarose and human plasminogen-free fibrin agar plates. The lysine adsorbable plasminogen activator was eluted with ammonium thiocyanate-containing buffer as described by Comp et al. (11) and assayed on the fibrin plates with added canine plasminogen. The euglobulin lysis time was performed by the method of Nilsson et al. (12), and fibrinolysis of whole blood clots was assessed by the method of Comp et al. using ${ }^{125}$ I-labeled fibrinogen (Amersham Corp., Arlington Heights, IL) (13).
Bovine Factor $\mathrm{X}$ and prothrombin were prepared by the methods of Bajaj and Mann (14). Factor $X$ was activated by immobiliżed purified Russell viper venom (kindly provided by Dr. W. Kissiel, University of Washington, Seattle, WA) by the method of Downing et al. (15). The concentrated stock solution of Factor $\mathrm{Xa}(1 \mathrm{mg} / \mathrm{ml})$ was stored in $50 \%$ glycerol at $-20^{\circ} \mathrm{C}$ and diluted with Tris- $\mathrm{HCl}(0.02 \mathrm{M})$ buffered saline $(0.15 \mathrm{M}), \mathrm{pH} 7.4$, containing polyethylene glycol (1\%) to the prescribed dose (see below) just before use. Bovine thrombin was prepared by the method of Lundblad et al. (16). PCPS lipid vesicles were prepared and assayed as previously described (17). The PCPS lipid vesicles were stored at $4^{\circ} \mathrm{C}$ and used within $10 \mathrm{~d}$ of preparation. The purified Factor $\mathrm{V}$ used was prepared from bovine plasma as previously described (18). This was labeled with carrier-free $\left[{ }^{125} \mathrm{I}\right]$ iodide (New England Nuclear, Boston, MA) by the method of Bolton and Hunter (19). Factor Va was prepared from the purified zymogen by thrombin activation as previously described (18). Protein $\mathrm{C}$ was prepared and activated with purified thrombin as described by Kisiel (20).

Animal studies. The animals used were mongrel dogs obtained from the Queen's University Animal Facility, Kingston, Ontario, Canada. Each animal was screened for coagulation abnormalities before inclusion in the studies. All were fed on dry dog chow and water, ad lib.

The cuticle bleeding time (CBT) was performed as previously described (7). This test is a reproducible and sensitive indicator of coagulation factor deficiencies (7; Giles, A. R., S. Tinlin, L. Brosseau, and $H$. Hoogendoorn, manuscript to be published). Unlike the skin bleeding time used in clinical practice, it is probably not sensitive to defects in primary hemostasis, i.e., platelet plug formation, although this has not been fully evaluated (unpublished observations).

In the studies described, the animals were lightly anesthetized with a rapid-acting intravenous barbiturate (Bio-Tal, Boehringer Ingelheim Ltd., Burlington, Ontario, Canada). In some cases, in which only blood samples were taken, the animals were not anesthetized. Vascular access was obtained via an indwelling 21-gauge butterfly needle placed in an anticubital vein. Between sampling, a continuous infusion of isotonic saline was maintained to keep the vein open. Prescribed doses of Factor Xa and PCPS lipid vesicles were mixed just before infusion and administered via a cannula placed in a different limb to that used for blood sampling.

Gel autoradiographic studies. Serial plasma samples after the infusion of ${ }^{125} \mathrm{I}$-labeled Factor Va were obtained as described in Results and electrophoresed in vertical-reduced polyacrylamide slab gels as previously described (21). As standard markers, Factor Va with and without activated protein C (APC) were run in parallel. Autoradiography on the completed gels was performed as previously described (21).

\section{Results}

Effects of administering a combination of Factor Xa and PCPS lipid vesicles to unanesthetized normal dogs. Fig. 1 shows the effects on the levels of fibrinogen, platelet count, and Factors $V$ and VIII:C after the intravenous infusion of Factor $\mathrm{Xa} / \mathrm{PCPS}$ at a dose of $6.6 \times 10^{-12}$ and $4.0 \times 10^{-8} \mathrm{~mol} / \mathrm{kg}$ body weight, respectively. The animals were not anesthetized and the infusion was given over $1 \mathrm{~min}$ by a 21 -gauge butterfly needle placed in the cubital vein of a forepaw. Preinfusion and 10- and 30-min postinfusion blood samples were obtained. The postinfusion samples were obtained by repeated veni- 


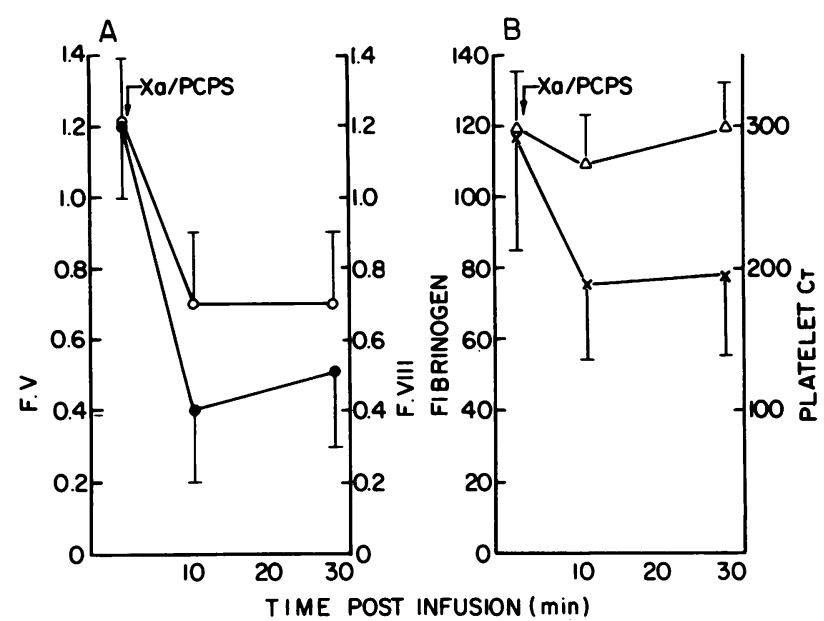

Figure 1. The effect of infusion of a combination of Factor Xa/PCPS lipid vesicles on coagulation parameters in six normal dogs. Factor $\mathrm{Xa} / \mathrm{PCPS}$ was infused into conscious normal dogs at a dose of 6.6 $\times 10^{-12}$ and $4.0 \times 10^{-8} \mathrm{~mol} / \mathrm{kg}$ body weight, respectively. Blood samples were obtained preinfusion and 10 and 30 min postinfusion. Mean and SD of platelet counts $\left(\times 10^{9} /\right.$ liter; $\left.\Delta\right)$, fibrinogen $(\mathrm{mg} / \mathrm{ml}$; $\times)$, Factor VIII $(U / \mathrm{ml} ; \bullet)$, and Factor V $(U / \mathrm{ml} ; \circ)$ are shown. Factors V (F. V) and VIII (F. VIII) were measured by a one-stage prothrombin time and APTT assay, respectively.

puncture from the other forepaw. The infusion of Factor $\mathrm{Xa}$ / PCPS was associated with a rapid fall of the levels of fibrinogen and Factors V and VIII:C. There was a transient minor reduction in platelet count at $10 \mathrm{~min}$ but this had normalized by $30 \mathrm{~min}$. Clinically, no untoward effects were noted and no bleeding occurred from the venipuncture sites.

Effect of infusion of Factor Xa/PCPS on CBT. Identical studies were performed on lightly-anesthetized animals $(n=6)$ so the effects on the CBT could be assessed. In this method, the apex of the cuticle was severed with a guillotine device and the time recorded from injury induction to the cessation of bleeding. Two tests were performed before the infusion of Factor Xa/PCPS in each study. In the experiment illustrated (Fig. 2), both tests were within the normal range previously established for normal animals (7). At $10 \mathrm{~min}$ and $1 \mathrm{~h}$ after infusion of Factor Xa/PCPS at a dose of $6.6 \times 10^{-12}$ and $4.0 \times 10^{-8} \mathrm{~mol} / \mathrm{kg}$ body weight, respectively, the CBT was prolonged and cautery with silver nitrate was required to stop bleeding. This was a consistent finding in additional studies in other animals although in some the CBT had normalized at $1 \mathrm{~h}$. The Factor $\mathrm{V}$ and VIII:C levels during the period of CBT abnormality were in the range of 12-32 and 4-25\% (pne-stage assays), respectively.

${ }^{125} I$-Factor $V$ in vivo tracer studies. ${ }^{125} \mathrm{I}$-labeled purified bovine Factor $\mathrm{V}$ was used to investigate the mechanisms responsible for the fall in Factor $V$ levels noted after the infusion of Factor Xa/PCPS. ${ }^{125} \mathrm{I}$-Factor $\mathrm{V}$ was infused as a rapid bolus at a dose of $7.7 \times 10^{-11} \mathrm{~mol} / \mathrm{kg}$ body weight into

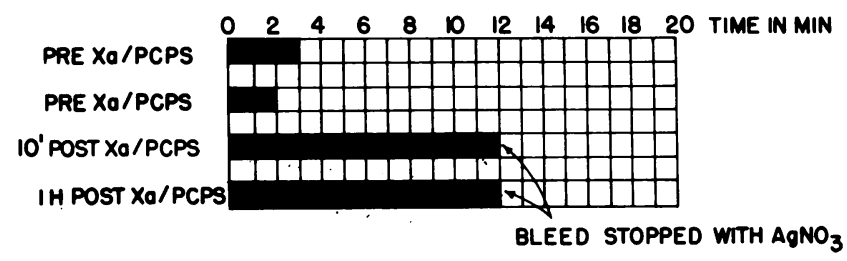

Figure 2. The effect of infusion of Factor $\mathrm{Xa}$ in combination with PCPS on the CBT in an anesthetized normal dog was determined. The CBT was measured twice before the infusion of Factor $\mathrm{Xa}$ $\left(6.6 \times 10^{-12} \mathrm{~mol} / \mathrm{kg}\right) / \mathrm{PCPS}\left(4.0 \times 10^{-8} \mathrm{~mol} / \mathrm{kg}\right)$, and repeated at 10 and $60 \mathrm{~min}$ postinfusion. Each horizontal bar shows the duration of bleeding in $\min$.

an anesthetized dog. Serum blood samples were obtained both before and after the infusion of Factor Xa/PCPS at a dose of $6.6 \times 10^{-12}$ and $4.0 \times 10^{-8} \mathrm{~mol} / \mathrm{kg}$ body weight, respectively. One-stage assays of Factor V and Factor VIII:C were performed on each sample as before, and the level of circulating radioactivity was determined by measuring plasma-associated radioactivity in a gamma counter (Beckman Instruments, Inc., Fullerton, CA). Additional samples were snap-frozen and subsequently analyzed on reduced polyacrylamide gels followed by autoradiography to detect activation/inactivation products of the isotopically-labeled Factor $\mathrm{V}$ infused.

The effect on Factor $\mathrm{V}$ level and circulating radioactivity is shown in Fig. 3. The infused ${ }^{125} \mathrm{I}$-Factor $\mathrm{V}$ was allowed to equilibrate for $30 \mathrm{~min}$ before the infusion of Factor Xa/PCPS. As before, the latter was associated with a rapid decrease in the Factor V level (one-stage assay) as shown. In contrast, no abrupt change in the levels of circulating radioactivity was noted after the infusion of Factor Xa/PCPS. This suggested that the radioactivity was either no longer associated with the infused intact Factor V, or that the precursor pool of Factor $\mathrm{V}$ was not affected, despite the findings of studies using a onestage assay.

Fig. 4 shows the results obtained with autoradiography performed on gels prepared from samples taken at the same time intervals before and after the infusion of Xa/PCPS. Thrombin-activated bovine Factor $\mathrm{V}$ and Factor Va plus APC were run in the same gel, $S_{1}$ and $S_{2}$, respectively. Comparison with these demonstrated that intact Factor $V$ persisted in the circulation after the infusion of Factor Xa/PCPS, confirming that the circulating radioactivity was still associated with the infused Factor V. No evidence of circulating ${ }^{125} \mathrm{I}$-Factor Va could be seen. However, from 2 min post-Factor Xa/PCPS, a faint but definite band was seen in position 12 suggesting proteolysis of the Factor Va heavy chain by APC. This suggested that ${ }^{125} \mathrm{I}$-Factor $\mathrm{V}$ was being activated but immediately inactivated by APC. A faint band running below band 12 is not well-visualized in the photoreproduction. This could be seen developing during the same time interval. This may represent an APC digest of the Factor Va heavy chain after this has been processed by platelets. We are uncertain of the 


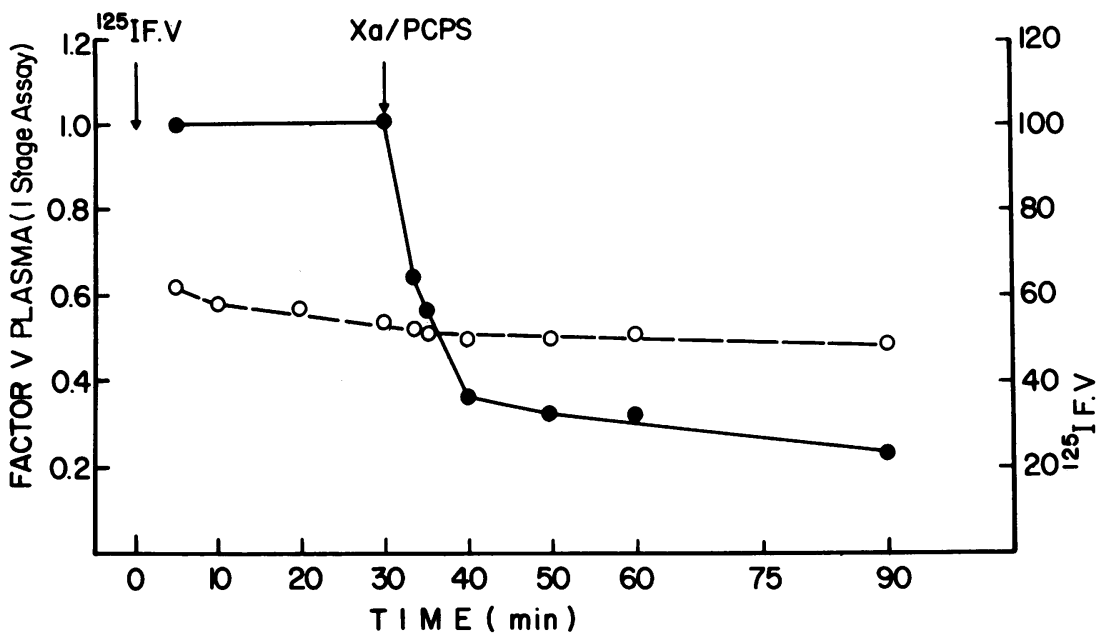

Figure 3. The effect of the infusion of Factor $\mathrm{Xa} / \mathrm{PCPS}$ on the clearance of ${ }^{125} \mathrm{I}$-Factor $\mathrm{V}$ (F. $\mathrm{V}$ ) in a normal dog. ${ }^{125} \mathrm{I}$-Factor $\mathrm{V}$ was infused into an anesthetized normal dog. Serial blood samples were taken at the time shown before and after the infusion of Factor $\mathrm{Xa}\left(6.6 \times 10^{-12}\right.$ $\mathrm{mol} / \mathrm{kg}) / \mathrm{PCPS}\left(4.0 \times 10^{-8} \mathrm{~mol} / \mathrm{kg}\right)$, and plasma radioactivity (O), and Factor $\mathrm{V}$ levels $(U / \mathrm{ml} ; \bullet)$ determined. Factor $\mathbf{V}$ assays were performed by a one-stage prothrombin time system. significance of the developing bands in positions 10 and 11 , but they may represent Factor Xa digest products of Factor Va light chain, i.e., band 6 .

Data suggested that the coagulation assays used were not measuring the quantity of available precursor Factor $\mathrm{V}$, and raised the possibility that the one-stage assay results reflected consumption of the activated fraction, i.e., Factor Va. To evaluate this hypothesis, a two-stage assay was developed in which the test samples were fully activated to Factor Va by prior incubation with a purified preparation of thrombin as described in Methods. The results obtained are shown in Fig. 5. Note that the amount of precursor Factor V, as measured by a two-stage assay, shows little change after the infusion of Factor Xa/PCPS in contrast to the fall in Factor V activity as

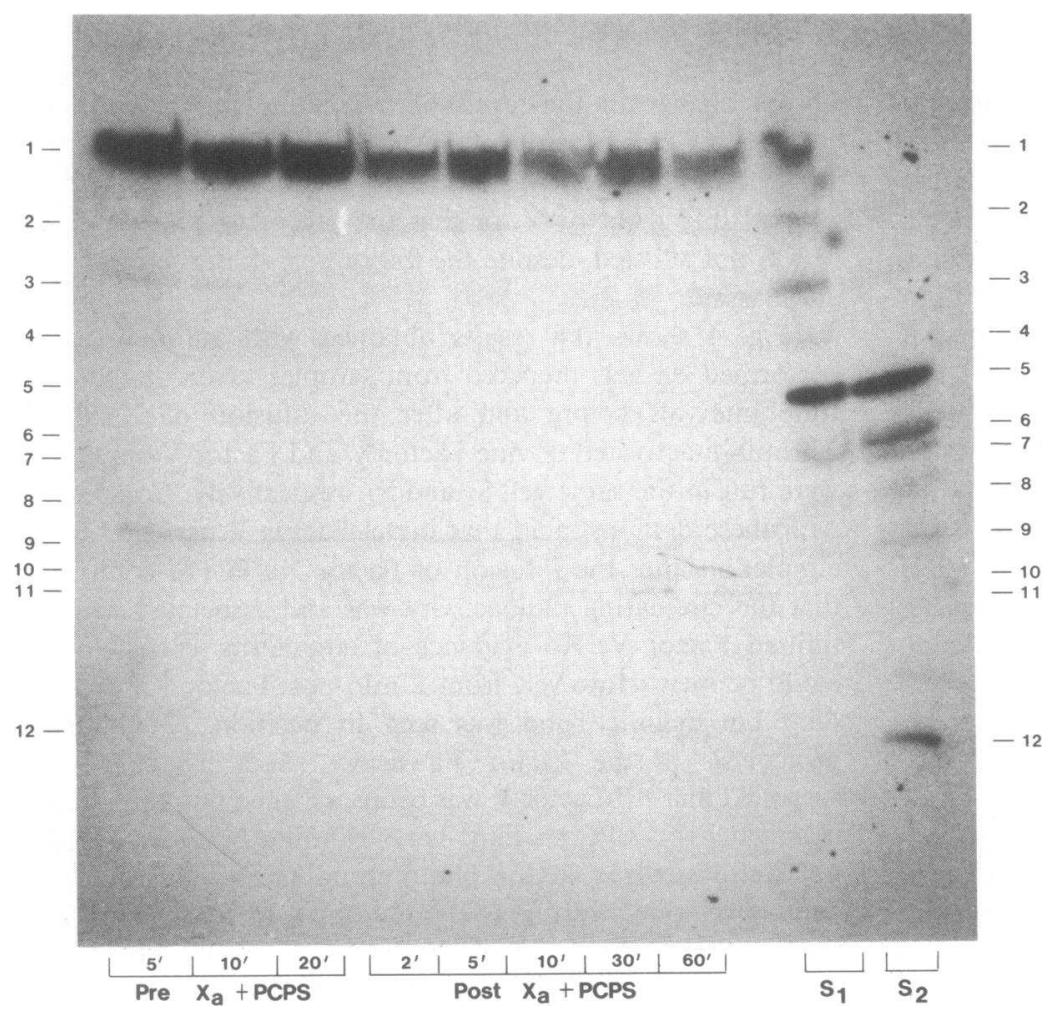

Figure 4. The effect of infusion of Factor Xa/PCPS on Factor $\mathrm{V}$ as determined by gel-autoradiographic studies. Gel autoradiographic studies were performed on plasma samples obtained from the experiment described in Fig. 3. Specimens obtained at 5, 10, and $20 \mathrm{~min}$ before and $2,5,10,30$, and $60 \mathrm{~min}$ after Factor $\mathrm{Xa} / \mathrm{PCPS}$ infusion were processed with two standards $\left(S_{1}\right.$ and $\left.S_{2}\right)$ in the same gel. Standard $S_{1}$ is ${ }^{125} \mathrm{I}$-Factor $\mathrm{V}$ activated by thrombin $(2 \mathrm{U} / \mathrm{ml}$

- final) at $37^{\circ} \mathrm{C}$ for $5 \mathrm{~min}$. Standard $S_{2}$ is the Factor Va used in $S_{1}$ after preincubation with activated protein C. Bands 5 and 6 are the $94 \mathrm{kD}$ heavy-chain and the $74 \mathrm{kD}$ light-chain of Factor Va, respectively. Band 7 is the activated protein $\mathrm{C}$ digest of band 5 , and band 12 is a further product. 


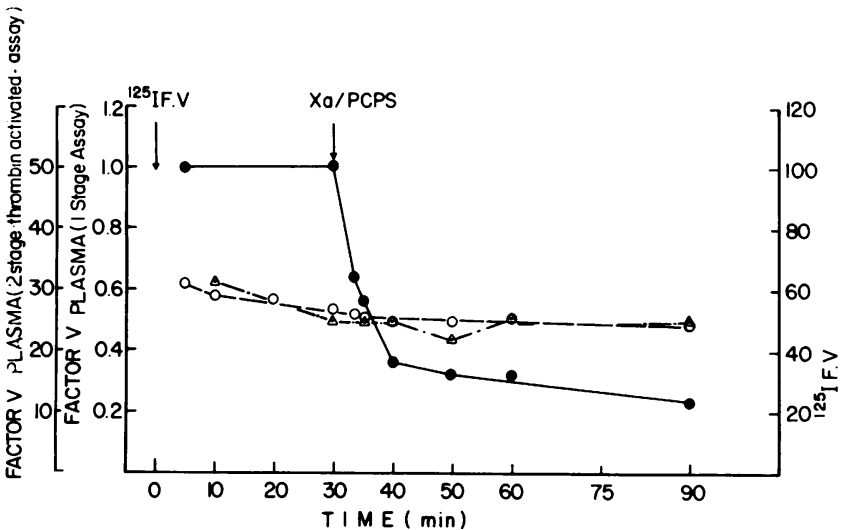

Figure 5. The effect of infusion of Factor Xa/PCPS on the levels of Factor V (F. V) determined by one- or two-stage assays. These data were obtained from the same experiment as those shown in Figs. 3 and 4. Plasma samples were obtained at the times shown following infusion of Factor Xa $\left(6.6 \times 10^{-12} \mathrm{~mol} / \mathrm{kg}\right) / \mathrm{PCPS}\left(4.0 \times 10^{-8}\right.$ $\mathrm{mol} / \mathrm{kg}$ ). $30 \mathrm{~min}$ after the infusion of ${ }^{125} \mathrm{I}$-Factor $\mathrm{V}$ circulating plasma radioactivity (0), Factor $\mathrm{V}$ one-stage assay $(\bullet)$, and Factor $\mathrm{V}$ twostage assay $(\Delta)$ were determined at the times shown. In the two-stage assay, the plasma samples were thrombin activated $(1 \mathrm{U} / \mathrm{ml}$ for 1 $\min$ at $37^{\circ} \mathrm{C}$ ) before being assayed as for the one-stage procedure.

measured by a one-stage assay. There is a close correlation in changes of Factor V levels, measured by a two-stage assay, over time and radioactivity associated with the infused ${ }^{125}$ I-Factor V. Repeat studies in a second animal produced almost identical findings.

Factor VIII:C studies. We could not perform tracer studies similar to those performed with Factor V with Factor VIII:C due to the unavailability of sufficient quantities of the purified protein. Nonetheless, we performed similar comparisons of Factor VIII:C levels assessed by one- and two-stage assays, and determined the effect of infusion of Factor Xa/PCPS as previously described. The results obtained in a typical experiment are shown in Fig. 6. In contrast to Factor V, note that the infusion of Factor Xa/PCPS produced a fall in Factor VIII:C as measured by both assay systems. However, the effect as measured by the two-stage assay was transient, and fairly rapid recovery took place. By $60 \mathrm{~min}$, the results were within the normal range for unanesthetized, normal resting animals. In contrast, the levels measured by one-stage assays remained depressed for the whole observation period.

Fibrinolytic assays. Levels of circulating plasminogen activator, measured as described in Methods, did not change during the observation period. Similarly, there was no evidence of enhanced fibrinolytic activity as assessed by either euglobulin lysis time or ${ }^{125}$ I-fibrin clot lysis.

Effect of heparinization on results of infusion of Factor $X a / P C P S$. Heparin was administered as an intravenous bolus of $50 \mathrm{U} / \mathrm{kg}$ body weight to anesthetized dogs. Preliminary studies were performed to determine the kinetics of heparin

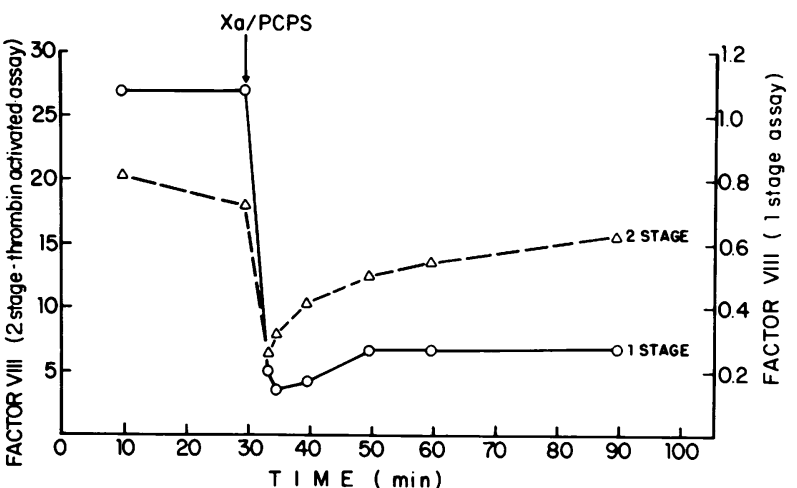

Figure 6. Plasma samples from experiment shown in Figs. 3-5 were assayed by one-stage $(U / \mathrm{ml} ; 0)$ and two-stage $(U / \mathrm{ml} ; \Delta)$ assays for Factor VIII at the time shown before and after the infusion of Factor $\mathrm{Xa}\left(6.6 \times 10^{-12} \mathrm{~mol} / \mathrm{kg}\right) / \mathrm{PCPS}\left(4.0 \times 10^{-8} \mathrm{~mol} / \mathrm{kg}\right)$. In the two-stage assay, plasma samples were activated with thrombin $(1 \mathrm{U} / \mathrm{ml}$ for 1 $\min$ at $37^{\circ} \mathrm{C}$ ) before being assayed as for the one-stage determination in an APTT system.

clearance in individual animals. Factor $\mathrm{Xa}$ and PCPS were then infused in separate experiments at the same dose as previously used. The timing of the infusion, postheparin, was based on a predicted heparin level of $0.2-0.4 \mathrm{U} / \mathrm{ml}$ plasma derived from the pilot kinetic studies in each animal. Heparin levels $>0.1 \mathrm{U} / \mathrm{ml}$ plasma totally inhibited the changes in fibrinogen and Factors V and VIII previously recorded in the absence of heparin.

\section{Discussion}

Our results demonstrate that the infusion of purified Factor $\mathrm{Xa}$ combined with coagulant-active phospholipid in the form of PCPS lipid vesicles is associated with a significant reduction in the levels of fibrinogen and Factors V and VIII:C when the latter were measured by one-stage assays. A bleeding diathesis was also observed. The latter was reproducible, although there were minor variations in degree from one animal to another. These changes bear a striking resemblance to those seen in patients with disseminated intravascular coagulation (1), particularly those developing this as a complication of treatment with prothrombin complex concentrates (4). The effect on platelet count was less impressive. However, in this model the phospholipid surface is presumably being provided by the PCPS lipid vesicles. In the clinical syndrome, platelet activation and recruitment is thought to be one of the common pathways or triggers for the initiation of DIC (1). Further studies will be required to elucidate this, and are either proposed or in progress.

If we are correct in assuming that this model simulates the hemostatic mechanisms operative in human DIC, our findings have important bearings on the understanding of its pathogenesis and subsequent management. The isotope tracer studies 
and the results obtained using two-stage assays of Factors $\mathbf{V}$ and VIII:C clearly demonstrate that there were minimal or transient changes in the precursor pools of Factors $\mathrm{V}$ and VIII:C, respectively. These data suggest that the one-stage assays of both Factors V and VIII reflect a substantial reduction in the levels of the activated fraction of each clotting factor, and that these are closely correlated with the clinical effect, i.e., a bleeding diathesis. While in vitro study has clearly shown the essential requirement for the activation of both Factors $V$ and VIII:C for each to exert its full cofactor activity, we believe that this is the first demonstration of this prerequisite in vivo.

Recent information regarding protein $\mathrm{C}$ has demonstrated its potent anticoagulant activity and that this is mediated via the inactivation of Factors Va and VIII:Ca $(22,23)$. The effects on these two activated cofactors in our studies led us to suspect that the infusion of Factor Xa/PCPS resulted in the in vivo activation of protein C. Autoradiography of gels prepared from sequential plasma samples from two dogs infused with ${ }^{125} \mathrm{I}$-Factor $\mathrm{V}$ followed by Factor Xa/PCPS supports this hypothesis. It is reasonable to suppose that the combination of Factor Xa/PCPS, in association with endogenous Factor $\mathrm{V}$ and ionized calcium, can generate thrombin in vivo. This could then activate protein $\mathrm{C}$ as demonstrated by Comp et al., who infused exogenous thrombin into dogs (24).

Our findings do not provide information as to the mechanism responsible for the fall in fibrinogen levels. Activated protein $\mathrm{C}$ has been shown to influence the circulating levels of plasminogen activator $(13,24)$. The precise mechanisms involved have not yet been defined. We do not believe that the fall in fibrinogen levels represented enhanced fibrinolysis or fibrinogenolysis, as neither the circulating levels of plasminogen activator nor fibrinolytic activity as assessed by euglobulin lysis time or whole blood clot lysis was increased. We believe it is more likely that the fibrinogen consumption represented conversion to fibrin as we have previously demonstrated that infusion of Factor Xa/PCPS is associated with a thrombotic tendency in a stasis model in rabbits (6).

Our findings of major reductions in the levels of Factors Va and VIII:Ca with little evidence of enhanced fibrinolytic activity contrast with those reported by Comp et al., who either activated protein $\mathrm{C}$ in vivo by infusing thrombin, or infused preactivated protein $C(13,24)$. This could be a function of the in vivo generation of thrombin. Alternatively, it is known that the inactivation of Factors V and VIII:C is enhanced significantly by the presence of coagulant-active phospholipid in vitro (25). The provision of this by PCPS may favor the anticoagulant rather than the fibrinolytic pathways controlled by protein $\mathrm{C}$. This will require further study.

In conclusion, we believe that the animal model described shows some major similarities to disseminated intravascular coagulation seen in clinical practice. Our data suggest that the consumption of Factors V and VIII:C that occurs during this process is, in fact, mainly consumption of the activated fractions rather than the precursor pools, and that one-stage assays of Factors V and VIII appear to be closely correlated to changes in the activated fractions of both cofactors. Evidence shows that this consumption is a function of the in vivo activation of protein $\mathrm{C}$, and that this can be inhibited by therapeutic levels of heparin. As thrombin is believed to be the physiological activator of protein $C$, it is reasonable to suppose that the benefit that may accrue from the use of heparin in DIC (26) may relate more to its ability to inhibit, in concert with antithrombin III, the thrombin activation of protein $\mathrm{C}$ rather than the conversion of fibrinogen to fibrin. Moreover, the recent demonstration of augmentation by heparin of the inhibition of activated protein $\mathrm{C}$ by its natural plasma inhibitor (27) would be another explanation for its mode of action. A functional assay of circulating activated protein $C$ levels would greatly facilitate the evaluation of this hypothesis in clinical practice.

\section{Acknowledgments}

The technical assistance of Hugh Hoogendoorn, Shawn Tinlin, and Lorraine Brosseau is gratefully acknowledged, as is the help of Mr. Stan Morton and Kathy Fluhrer in the preparation of the manuscript. This work was supported by grants from the Medical Research Council of Canada (MA7667), the National Health Research and Development Program of Canada, the National Institutes of Health (HL-17430, HL-26070, and HL-30365), The Mayo Foundation, The Dean's Fund, Queen's University, and Alpha Therapeutic Corp., Los Angeles, CA.

\section{References}

1. Sharp, A. A. 1977. Diagnosis and management of disseminated intravascular coagulation. Br. Med. Bull. 33:265-272.

2. Blatt, P. M., R. L. Lundblad, H. S. Kingdon, G. McLean, and H. R. Roberts. 1974. Thrombogenic materials in prothrombin complex concentrates. Ann. Intern. Med. 81:766-770.

3. Kasper, C. K. 1975. Thromboembolic complications (Task Force Report-International Society of Thrombosis and Hemostasis). Thromb. Diath. Haemorrh. 33:640-644.

4. Giles, A. R., M. A. Blajchman, J. Hirsh, M. Johnston, and T. Seaton. 1977. DIC following Factor IX complex (Connaught) infusion in a patient with liver disease. Ann. R. Coll. Physicians Surg. Can. 10:57a. (Abstr.)

5. White, G. C., H. R. Roberts, H. S. Kingdon, and R. L. Lundblad. 1977. Prothrombin complex concentrates: potentially thrombogenic materials and clues to the mechanism of thrombosis in vivo. Blood. 49:159-170.

6. Giles, A. R., M. E. Nesheim, H. Hoogendoorn, P. B. Tracy, and K. G. Mann. 1982. The coagulant-active phospholipid content is a major determinant of in vivo thrombogenicity of prothrombin complex (Factor IX) concentrate in rabbits. Blood. 59:401-407.

7. Giles, A. R., S. Tinlin, and R. Greenwood. 1982. A canine model of hemophilic (Factor VIII:C deficiency) bleeding. Blood. 60:727730.

8. Nesheim, M. E., J. A. Katzman, P. B. Tracy, and K. G. Mann. 1981. Factor V. Methods Enzymol. 80:249-274.

9. Clauss, V. A. 1957. Gerinnungsphysiologische schnellmethode zur bestimung des fibrinogens. Acta Haematol. 17:237-246.

10. Teien, A. N., and M. Lie. 1977. Evaluation of an amidolytic heparin assay method: increased sensitivity by adding purified antithrombin III. Thromb. Res. 10:399-410. 
11. Comp, P. C., R. M. Jacocks, C. Rubenstein, and R. Radcliffe. 1981. A specific circulating plasminogen activator, or class of activators, is elevated in conditions associated with increased fibrinolytic activity. J. Lab. Clin. Med. 97:637-649.

12. Nilsson, I. M., U. Hedner, and M. Pandolfi. 1978. The measurement of fibrinolytic activities. In Fibrinolytics and Anti-fibrinolytics. F. Markwardtf, editor. Springer-Verlag, Berlin. 107-134.

13. Comp, P. C., and N. Esmon. 1981. Generation of fibrinolytic activity by infusion of activated Protein C into dogs. J. Clin. Invest. 68:1221-1228.

14. Bajaj, S. P., and K. G. Mann. 1973. Simultaneous purification of bovine prothrombin and Factor X: activation of prothrombin by trypsin-activated Factor X. J. Biol. Chem. 248:7729-7741.

15. Downing, M. R., R. J. Butkowski, M. M. Clark, and K. G. Mann. 1975. Human prothrombin activation. J. Biol. Chem. 250:88978906.

16. Lundblad, R. L., R. C. Uhteg, C. N. Vogel, H. S. Kingdon, and K. G. Mann. 1975. Preparation and partial characterization of two forms of bovine thrombin. Biochem. Biophys. Res. Commun. 66:482-489.

17. Nesheim, M. E., J. B. Taswell, and K. G. Mann. 1979. The contribution of bovine Factor $\mathrm{V}$ and Factor $\mathrm{Va}$ to the activity of prothrombinase. J. Biol. Chem. 254:10952-10983.

18. Nesheim, M. E., K. H. Myrmel, L. Hibbard, and K. G. Mann. 1979. Isolation and characterization of single-chain bovine Factor V. J. Biol. Chem. 254:508-517.
19. Bolton, A. E., and W. M. Hunter. 1973. The labelling of proteins to high specific radioactivities by conjugation to a ${ }^{125} \mathrm{I}$-containing acylating agent. Biochem. J. 133:529-539.

20. Kisiel, W., and E. W. Davie. 1981. Protein C. Methods Enzymol. 80:320-332.

21. Tracy, P. B., M. E. Nesheim, and K. G. Mann. 1983. Proteolytic alterations of Factor Va bound to platelets. J. Biol. Chem. 258:662-669.

22. Kisiel, W., W. M. Canfield, L. H. Ericsson, and E. W. Davie. 1977. Anticoagulant properties of bovine Protein $\mathrm{C}$ following activation by thrombin. Biochemistry. 16:5824-5831.

23. Marlar, R. A., A. J. Kleiss, and J. H. Griffin. 1980. Anticoagulant action of human Protein C. Protides Biol. Fluids Proc. Colloq. 28:341345.

24. Comp, P. C., R. M. Jacocks, G. L. Ferrell, and C. T. Esmon. 1982. Activation of Protein C in vivo. J. Clin. Invest. 70:127-134.

25. Walker, F. J., P. W. Sexton,, and C. T. Esmon. 1979. The inhibition of blood coagulation by activated Protein $C$ through selective inactivation of activated Factor V. Biochim. Biophys. Acta. 571:333342.

26. Deykin, D. 1970. The clinical challenge of disseminated intravascular coagulation. $N$. Engl. J. Med. 283:636-644.

27. Canfield, W. M., and Kisiel, W. 1982. Evidence of normal functional levels of activated protein $\mathrm{C}$ inhibitor in combined Factor V/VIII deficiency disease. J. Clin. Invest. 70:1260-1272. 